\title{
ALCOHOL CONSUMPTION AND ALL-CAUSE MORTALITY: AN ANALYSIS OF GENERAL PRACTICE DATABASE RECORDS FOR PATIENTS WITH LONG TERM CONDITIONS
}

Dr Duncan Stewart ${ }^{1}$

Senior Lecturer in Addictive Behaviours \& Public Health

Department of Health Sciences

University of York

Heslington, YO10 5DD

duncan.stewart@york.ac.uk

Dr Lu Han

Research Fellow

Department of Health Sciences

University of York

Heslington, YO10 5DD

Prof Tim Doran

Professor of Health Policy

Department of Health Sciences

University of York

Heslington, YO10 5DD

Prof Jim McCambridge

Professor in Addictive Behaviours \& Public Health

Department of Health Sciences

University of York

Heslington, YO10 5DD

${ }^{1}$ Lead author and Guarantor

Keywords: Alcohol, mortality, general practice, smoking, deprivation

Word count: 2940

References: 27 


\section{Copyright:}

The Corresponding Author has the right to grant on behalf of all authors and does grant on behalf of all authors, a worldwide licence to the Publishers and its licensees in perpetuity, in all forms, formats and media (whether known now or created in the future), to i) publish, reproduce, distribute, display and store the Contribution, ii) translate the Contribution into other languages, create adaptations, reprints, include within collections and create summaries, extracts and/or, abstracts of the Contribution, iii) create any other derivative work(s) based on the Contribution, iv) to exploit all subsidiary rights in the Contribution, $v$ ) the inclusion of electronic links from the Contribution to third party material where-ever it may be located; and, vi) licence any third party to do any or all of the above.

\section{Licence for Publication}

The Corresponding Author has the right to grant on behalf of all authors and does grant on behalf of all authors, an exclusive licence (or non exclusive for government employees) on a worldwide basis to the BMJ Publishing Group Ltd to permit this article (if accepted) to be published in JECH and any other BMJPGL products and sublicences such use and exploit all subsidiary rights, as set out in our licence (http://group.bmj.com/products/journals/instructions-for-authors/licence-forms).

Competing Interests: None declared. 


\begin{abstract}
Background

Alcohol is a risk factor for ill health and reduced life expectancy, but little is known about the impact of alcohol on mortality for people with existing long term conditions. We used primary care data from the Clinical Practice Research Datalink (CPRD) to study relationships between alcohol consumption and all-cause mortality among general practice patients with long term conditions.
\end{abstract}

Methods

Data were accessed from a sample of 125 general practices from the CPRD database. Adult patients with long term health conditions, a record of alcohol consumption in CPRD, and at least 1 year of follow-up data between 2000 and $2014(n=95,991)$ were matched to the Office for National Statistics (ONS) mortality register.

Results

In Cox proportional hazards regression models, mortality was higher for patients consuming 25-34 units of alcohol per week (hazard ratio [HR] 1.26, 95\% CI 1.12 to 1.42) and 35 units or more (HR $1.71,95 \%$ CI 1.51 to 1.94 ), compared to those drinking 1-7 units per week. Patterns of mortality risk were the same for men and women. Heavy drinking increased mortality risk in combination with smoking (HR 4.04, 95\% CI 3.41-4.79) and high levels of deprivation (HR 3.01, 95 CI 2.40-3.79).

\title{
Conclusions
}

Heavier drinkers with long term conditions are at significantly greater risk of death than lighter drinkers. The findings support the UK Chief Medical Officers' guidance on having similar low risk alcohol consumption guidelines for men and women. More needs to be done to tackle alcohol consumption among patients with long term conditions. 


\section{INTRODUCTION}

Alcohol consumption places a major burden on population health and health services. It is associated with over 200 health conditions, contributes to $5.9 \%$ of deaths globally,(1) and is the fifth greatest risk factor for ill health and reduced life expectancy in the UK,(2) with over one million alcohol related hospital admissions recorded annually in England.(ㄱ) Annual costs to the National Health Service (NHS) are estimated to be $£ 3$ billion,(4) and overall costs to society in excess of $£ 20$ billion.(ㅁ) An estimated 23,000 deaths per annum in England are wholly or partly attributable to alcohol: 65 per 100,000 men and 29 per 100,000 women.()ㅡ

General practitioners (GPs) are well placed to identify and help people with alcohol problems, particularly patients with long term conditions who regularly interact with the practice. However, evidence suggests that opportunities for timely intervention with patients are being missed: levels of screening for excessive alcohol consumption are low, $(\underline{6}, \underline{7})$ with less than one in ten excessive drinkers receiving any advice about their alcohol consumption.(ㅇ) Important uncertainties persist about how to intervene on alcohol in general practice due to weaknesses in available evidence.(ㅁ)

Research in primary care has been significantly enhanced by the availability of anonymised individual patient databases, which allow analysis of the routine management and health outcomes of large samples of patients. However, previous studies based on primary care databases have focussed on single alcohol-related diseases (such as alcoholic cirrhosis),(10) identification of alcohol use disorders,(ㅁ) or have simply included alcohol as a covariate in analyses of other health problems. Patterns of consumption are rarely studied in primary care databases, and only one study has addressed associations between alcohol consumption and health outcomes.(11) In this retrospective cohort study, we used the Clinical Practice Research Datalink (CPRD) to examine the relationship between levels of alcohol consumption and all-cause mortality among a sample of general practice patients with long term conditions. This patient population is already at increased risk of mortality, and our aim was to quantify the additional risk associated with alcohol consumption.

\section{METHOD}

\section{Data source}

CPRD contains anonymised information on patients' diagnoses, tests, treatments, prescriptions and referrals. We accessed a sample of 125 general practices from the CPRD database. Practices were selected to be nationally representative in terms of area deprivation and list size. Up to 2,500 patients with one or more long term conditions (including cancer, coronary heart disease, diabetes and hypertension) were randomly sampled from each practice. The final CPRD dataset used in this study 
contains records for 305,033 patients. All-cause mortality data were obtained from linked ONS mortality registration data (for patients eligible to have a death registration record).

\section{Participants}

Potentially eligible patients $(n=253,066)$ were identified from records of alcohol consumption in the CPRD dataset. These were extracted from clinical data files, and specific information on drinking status and weekly units consumed (1 UK unit is defined as 8 grams of alcohol) was obtained from a matched additional data extract. For each patient with alcohol consumption data, the most recent alcohol record during the follow-up period was selected. CPRD records drinking status as 'yes', 'no' and 'ex'. Patients recorded as drinkers but consuming zero units and those recorded as non-drinkers were combined for the purposes of these analyses (after confirming similar levels of mortality). Where alcohol consumption data were missing, the most recent available record was used.

Nevertheless, a substantial proportion of patients recorded as drinkers did not have a weekly alcohol consumption measure, and these patients were retained and recorded as missing in our analyses to avoid selection bias. We restricted our analysis to adults ( $\geq 18$ years), with a long term condition diagnosis recorded during the follow-up period, and at least one year of follow-up data starting from 1 January 2000, the date of registration at a participating practice or the date at which the practice was recorded as 'up to standard', whichever was later (the up to standard date is the date at which a practice is deemed to be of sufficient research quality to be included in CPRD). The final sample comprised 95,991 patients. These patients were followed up until they transferred out of the practice, until death, or to the end of the study period (30 November 2014), whichever was earlier. The mean length of follow-up was $8.2(\mathrm{SD}=4.1)$ years. Identifying Read codes for long term conditions are available from the Clinical Codes Repository (https://clinicalcodes.rss.mhs.man.ac.uk/).

\section{Covariates}

Covariates included in the analyses were: age; age $^{2}$; sex (coded 1 for male); Index of Multiple Deprivation 2010 quintiles (12) applied to patient postcode, with quintile 5 representing greatest deprivation; smoking status, using the most current available smoking record and categorised as smoker or non/ex-smoker; and the presence or absence of each long term condition: cancer, coronary heart disease, chronic kidney disease, chronic obstructive pulmonary disease (COPD), dementia, depression, diabetes, epilepsy, heart failure, hypertension, severe mental illness and stroke.

\section{Statistical analysis}

All-cause mortality rates for patients categorised by their alcohol consumption were modelled with Cox proportional hazards regression under three conditions. The first model adjusted for age. The second model adjusted for age and sex. The third model adjusted for measured covariates as follows: age, age ${ }^{2}$, sex, the presence or absence of long term conditions recorded during the study period (see Table 1), deprivation and smoking status. All Cox regression models were adjusted for clustering by 
practice (with robust standard errors) and hazard ratios with 95\% confidence intervals were calculated. Interaction terms were added to the full models, for alcohol consumption and smoking, and alcohol consumption and deprivation. Interactions were evaluated with Wald tests. The proportional hazards function assumption was tested by inspection of Schoenfeld residuals plotted against $\log$ (time). Sensitivity analyses were conducted to: 1) compare findings with a missing alcohol consumption category to those which used multiple imputation to handle missing data: and 2) limit the follow-up period to April 2004 onwards when the Quality and Outcomes Framework financial incentives scheme was introduced into primary care. For the former, we created 5 imputed datasets including outcome status and all potential confounders. Cox proportional hazards models were fitted to each dataset and estimates combined using Rubin's rules.(13) All analyses were conducted with Stata 14.

\section{RESULTS}

\section{Characteristics of the sample and unadjusted mortality rates}

The demographic and clinical charactersitics of the sample are described in Table 1. The largest groups were patients who consumed small amounts of alcohol (1-7 units per week; 30\%) and patients categorised as non-drinkers (29\%). Patients in the heavier drinking categories were younger on average and much more likely to be male: four out of five patients in the $35+$ weekly units category were male compared to one third of non-drinkers. There was also a clear association between alcohol consumption and smoking, with the proporton of patients recorded as current smokers increasing with consumption, up to $43 \%$ among those drinking $35+$ units per week.

Of the two highest prevalence health conditions in the sample, there was no clear relationship between drinking alcohol and hypertension, but for depression the highest rates were found for the heaviest drinking group and among ex-drinkers. A greater proportion of ex-drinkers, non-drinkers and the 35+ units group were from areas in the most deprived fifth of areas. The profile of patients with missing alcohol data most closely resembled the non-drinking category, particlularly in terms of demographic characteristics.

A total of 13,796 patients died during the study period. Crude all cause mortality rates per 1000 patient years fell with increasing alcohol consumption among low level drinkers, but as drinking increased above 25 units per week for men and women, so did the death rate (Table 2). The highest rates were for non drinkers and ex-drinkers, and rates were lower for women than men (with the exception of the ex-drinker category). 
Table 1: Characteristics of patients by alcohol consumption category

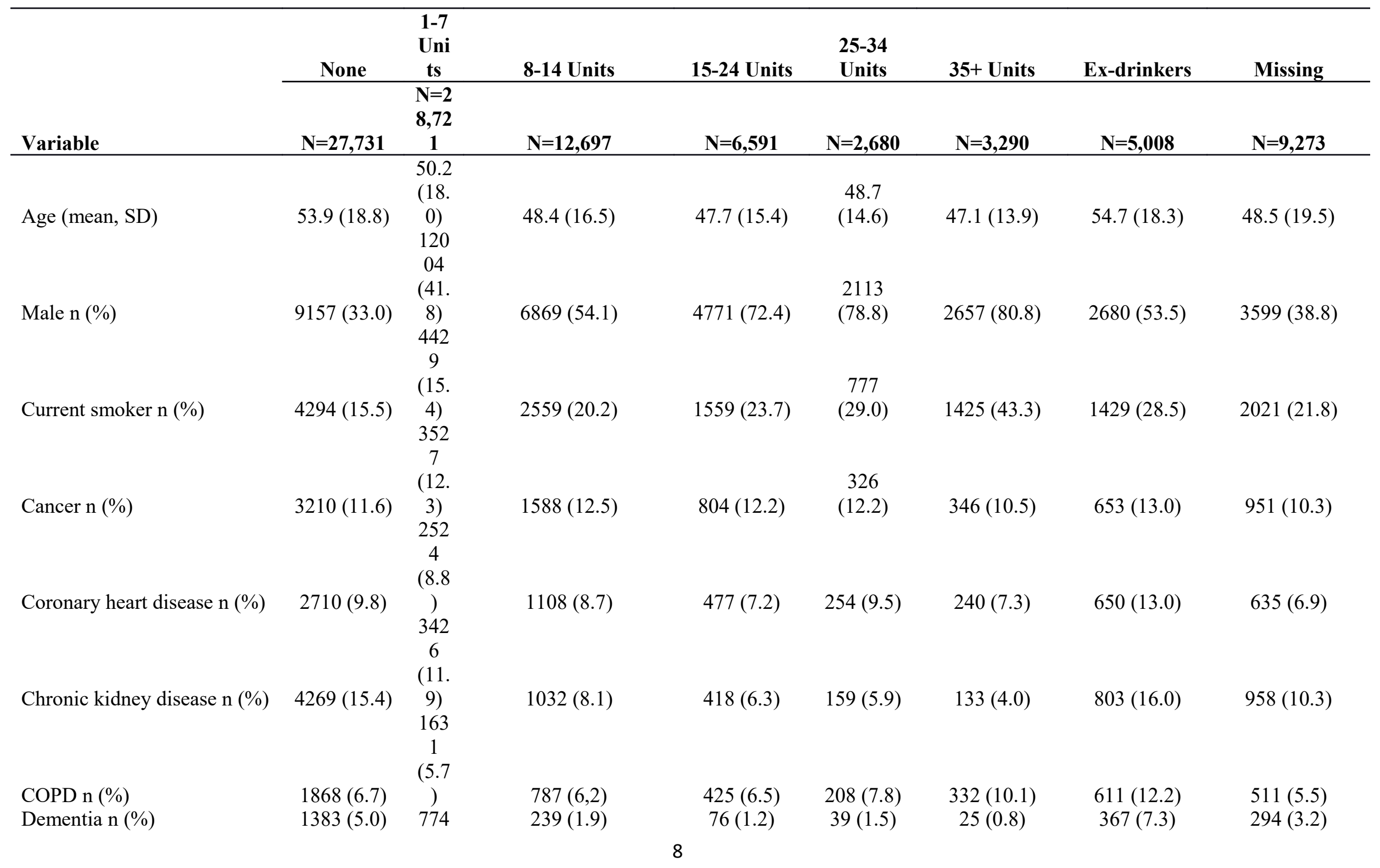




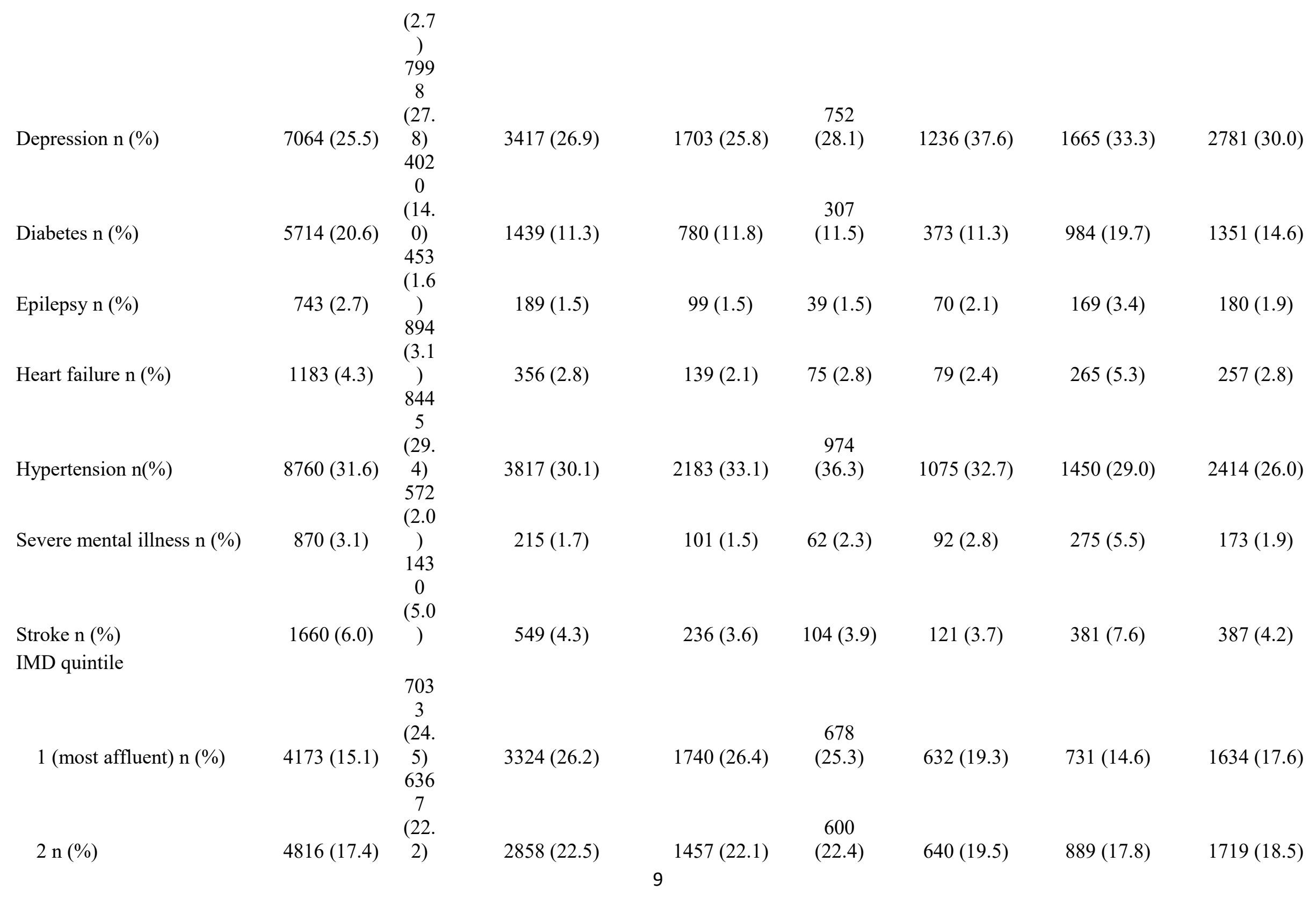




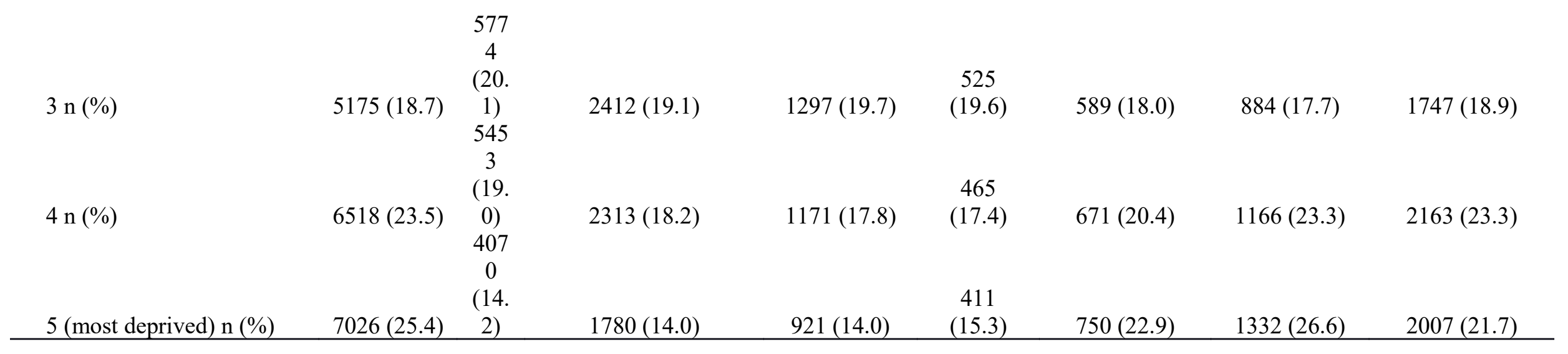


Table 2: Number of deaths and crude all-cause mortality rates by alcohol consumption category

\begin{tabular}{llccccc}
\hline & Units & Deaths & $\begin{array}{c}\text { Person } \\
\text { years }\end{array}$ & Rate $^{1}$ & & 95\%CI \\
\hline All & $1-7$ & 3545 & 243431 & 14.56 & 14.09 & 15.05 \\
& $8-14$ & 1331 & 108021 & 12.32 & 11.68 & 13.00 \\
& $15-24$ & 582 & 56620 & 10.28 & 9.48 & 11.15 \\
& $25-34$ & 315 & 23448 & 13.43 & 12.03 & 15.00 \\
& $35+$ & 463 & 27732 & 16.70 & 15.24 & 18.29 \\
& None & 5042 & 223475 & 22.56 & 21.95 & 23.19 \\
& Ex-drinker & 1177 & 39441 & 29.84 & 28.19 & 31.60 \\
& Missing & 1341 & 64281 & 20.86 & 19.77 & 22.01 \\
\hline Men & $1-7$ & 1796 & 102014 & 17.61 & 16.81 & 18.44 \\
& $8-14$ & 889 & 58590 & 15.17 & 14.21 & 16.20 \\
& $15-24$ & 460 & 40988 & 11.22 & 10.24 & 12.30 \\
& $25-34$ & 259 & 18487 & 14.01 & 12.40 & 15.82 \\
& $35+$ & 394 & 22264 & 17.70 & 16.03 & 19.53 \\
& None & 1753 & 73161 & 23.96 & 22.87 & 25.11 \\
& Ex-drinker & 627 & 21036 & 29.81 & 27.56 & 32.23 \\
& Missing & 552 & 24425 & 22.60 & 20.79 & 24.57 \\
\hline Women & $1-7$ & 1749 & 141418 & 12.37 & 11.80 & 12.96 \\
& $8-14$ & 442 & 49431 & 8.94 & 8.15 & 9.82 \\
& $15-24$ & 122 & 15632 & 7.80 & 6.54 & 9.32 \\
& $25-34$ & 56 & 4960 & 11.29 & 8.69 & 14.67 \\
& $35+$ & 69 & 5468 & 12.62 & 9.97 & 15.98 \\
& None & 3289 & 150314 & 21.88 & 21.15 & 22.64 \\
& Ex-drinker & 550 & 18405 & 29.88 & 27.49 & 32.49 \\
& Missing & 789 & 39856 & 19.80 & 18.46 & 21.23 \\
\hline
\end{tabular}

${ }^{1}$ Rate per 1000 person years

\section{Alcohol and risk of mortality}

We used Cox proportional hazards models to calculate hazard ratios for each alcohol consumption group, with the reference category being patients who consumed 1-7 unit units of alcohol per week (Table 3). Adjusting for age (Model 1), hazard ratios increased with consumption, peaking at 2.29 (95\% CI: 2.03-2.59) for patients comsuming 35 or more units per week, compared with patients consuming 1-7 units. Adjusting for age, age ${ }^{2}$ and sex (Model 2), there was little increased risk of mortality up to 15-24 units per week, but risk increased sharply at higher levels of consumption. There was a similar pattern after controlling for all study covariates (Model 3), but increased risk was attenuated at higher consumption levels: the hazard ratio for the 35+ units per week group was 1.71 (95\% CI: 1.51-1.94). In all three models, mortality risk was highest for patients drinking $35+$ units per week. Rates were elevated in all models for ex-drinkers, non-drinkers and for patients with missing data. 
Table 3: Hazard ratios for all-cause mortality by alcohol consumption category

\begin{tabular}{|c|c|c|c|c|c|c|}
\hline Units & $\begin{array}{c}\text { Model 1 } \\
\text { HR (95\% } \\
\text { CI) } \\
\end{array}$ & $\mathbf{P}$ & $\begin{array}{c}\text { Model 2 } \\
\text { HR (95\% } \\
\text { CI) } \\
\end{array}$ & $\mathbf{P}$ & $\begin{array}{c}\text { Model } 3 \\
\text { HR (95\% } \\
\text { CI) } \\
\end{array}$ & $\mathbf{P}$ \\
\hline $1-7^{*}$ & 1 & & 1 & & 1 & \\
\hline $8-14$ & $\begin{array}{l}1.08(1.00- \\
1.17)\end{array}$ & 0.031 & $\begin{array}{l}1.04(0.97- \\
1.12)\end{array}$ & 0.268 & $\begin{array}{l}0.99(0.93- \\
1.06)\end{array}$ & 0.837 \\
\hline $15-24$ & $\begin{array}{l}1.12(1.02- \\
1.24)\end{array}$ & 0.023 & $\begin{array}{l}1.02(0.93- \\
1.13)\end{array}$ & 0.641 & $\begin{array}{l}0.99(0.90- \\
1.10)\end{array}$ & 0.908 \\
\hline 25-34 & $\begin{array}{l}1.49(1.32- \\
1.69)\end{array}$ & $<0.001$ & $\begin{array}{l}1.35(1.19- \\
1.53)\end{array}$ & $<0.001$ & $\begin{array}{l}1.26(1.12- \\
1.42)\end{array}$ & $<0.001$ \\
\hline $35+$ & $\begin{array}{l}2.29(2.03- \\
2.59)\end{array}$ & $<0.001$ & $\begin{array}{l}2.05(1.82- \\
2.31)\end{array}$ & $<0.001$ & $\begin{array}{l}1.71(1.51- \\
1.94)\end{array}$ & $<0.001$ \\
\hline None & $\begin{array}{l}1.23(1.15- \\
1.31)\end{array}$ & $<0.001$ & $\begin{array}{l}1.29(1.21- \\
1.38)\end{array}$ & $<0.001$ & $\begin{array}{l}1.23(1.16- \\
1.31)\end{array}$ & $<0.001$ \\
\hline Ex-drinker & $\begin{array}{l}1.65(1.49- \\
1.82)\end{array}$ & $<0.001$ & $\begin{array}{l}1.64(1.49- \\
1.81)\end{array}$ & $<0.001$ & $\begin{array}{l}1.48(1.36- \\
1.62)\end{array}$ & $<0.001$ \\
\hline Missing & $\begin{array}{l}1.41(1.29- \\
1.56)\end{array}$ & $<0.001$ & $\begin{array}{l}1.47(1.33- \\
1.62)\end{array}$ & $<0.001$ & $\begin{array}{l}1.44(1.32- \\
1.57)\end{array}$ & $<0.001$ \\
\hline
\end{tabular}

* Baseline group

Model 1: Adjusted for age and age ${ }^{2}$

Model 2: Adjusted for age, age ${ }^{2}$ and sex

Model 3: Adjusted for age, age ${ }^{2}$, sex, Index of Multiple Deprivation quintiles, current smoking status and the presence or absence of the following long term conditions: cancer, coronary heart disease, chronic kidney disease, COPD, dementia, depression, diabetes, epilepsy, heart failure, hypertension, severe mental illness, stroke.

Covariates in Model 3 associated with significantly increased risk of mortality were age (HR=1.02, 1.01-1.04), sex (male $H R=1.28,1.24-1.33$ ), smoking ( $H R=2.11,2.00-2.23)$, greater deprivation (most deprived quintile $\mathrm{HR}=1.41,1.25-1.58)$, cancer ( $\mathrm{HR}=1.67,1.57-1.77)$, $\mathrm{COPD}(\mathrm{HR}=1.28,1.20-1.36)$, dementia $(\mathrm{HR}=1.19,1.11-1.28)$, heart failure $(\mathrm{HR}=1.39,1.29-1.50)$, severe mental illness $(\mathrm{HR}=1.33$, 1.15-1.53), stroke $(\mathrm{HR}=1.09,1.03-1.16)$ and epilepsy $(\mathrm{HR}=1.64,1.32-2.05)$. Full results are shown in Supplementary Table S1. Risk was significantly reduced for patients diagnosed with chronic kidney disease $(\mathrm{HR}=0.74,0.69-0.80)$ and hypertension $(\mathrm{HR}=0.69,0.65-0.73)$. These analyses were repeated with missing data handled by multiple imputation and for data from April 2004 only (Supplementary Table S2). In both cases, associations between categories of drinking and mortality risk were consistent with those found in the main analyses.

Given the large differences in the proportions of men and women in the drinking categories, separate analyses were conducted for male and female patients (Table 4). Although a substantially greater proportion of women were non-drinkers or low level drinkers, the pattern of mortality risk for the alcohol consumption groups was similar. Risk was significantly increased for non-drinkers and exdrinkers, patients drinking $35+$ units and for patients with missing data among women. The age adjusted hazard ratio for the 25-34 units group was higher for both men and women, but did not reach statistical significance in the full model for women. 
Table 4: Hazard ratios for all-cause mortality by alcohol consumption category for men and women

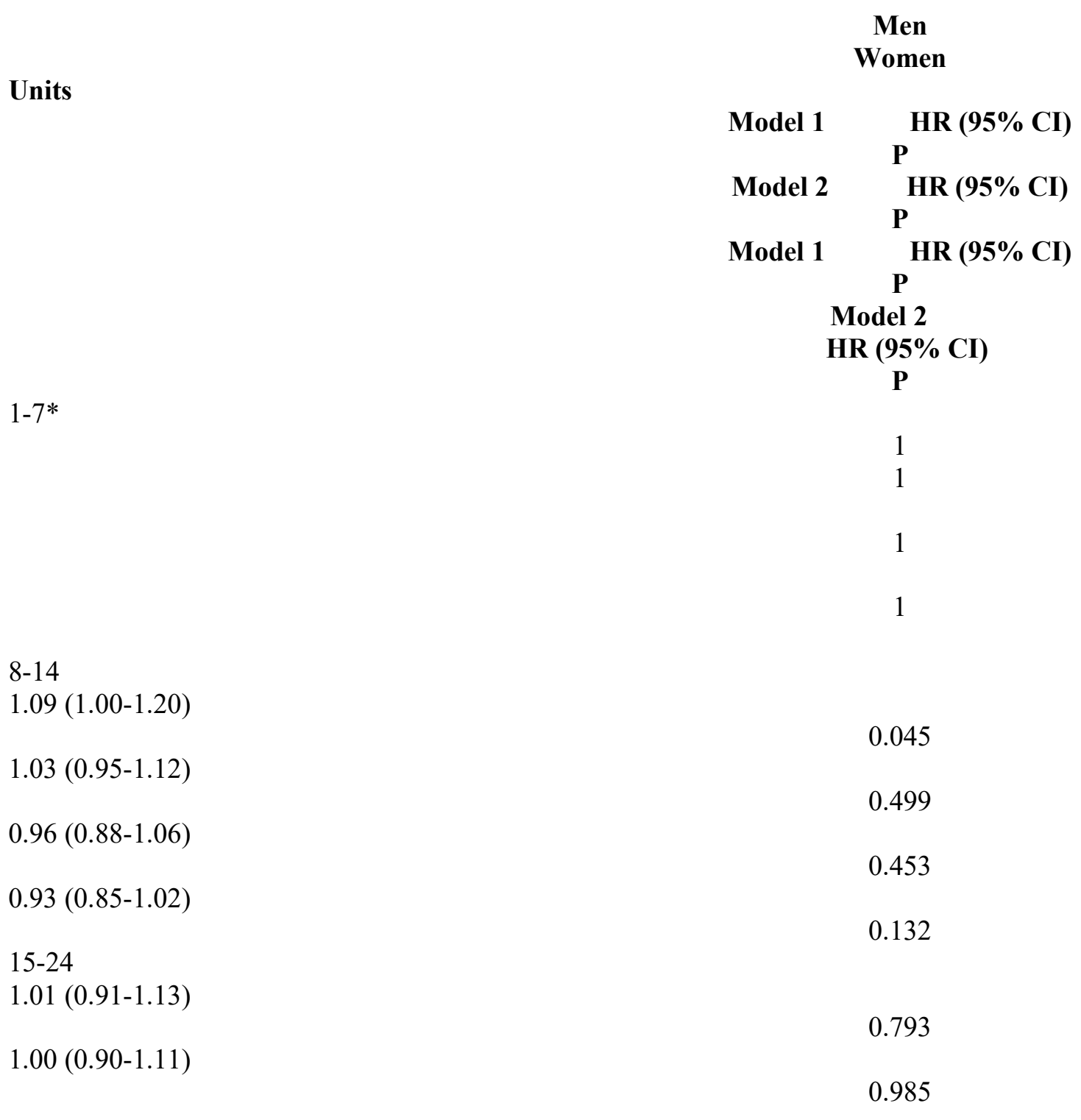




$\begin{array}{lc}1.09(0.90-1.34) & 0.357 \\ 1.00(0.82-1.23) & 0.983 \\ 25-34 & <0.001 \\ 1.34(1.18-1.53) & <0.001 \\ 1.28(1.12-1.45) & 0.014 \\ 1.41(1.07-1.87) & 0.224 \\ 1.18(0.90-1.55) & \\ 35+ & <0.001 \\ 2.01(1.76-2.30) & <0.001 \\ 1.69(1.48-1.94) & <0.001 \\ 2.30(1.76-3.01) & 0.001 \\ 1.65(1.24-2.20) & <0.001 \\ \text { None } & <0.001 \\ 1.34(1.23-1.47) & <0.001 \\ 1.26(1.16-1.38) & <0.001 \\ 1.24(1.16-1.32) & <01 \\ 1.20(1.12-1.28) & \\ \text { Ex-drinker } & \\ 1.71(1.52-1.91) & \\ 1.48(1.33-1.65) & \\ & \\ & \\ & \end{array}$


$1.55(1.37-1.76)$

$1.46(1.30-1.65)$

$<0.001$

Missing

$1.59(1.42-1.78)$

$1.52(1.36-1.70)$

$<0.001$

$1.37(1.21-1.54)$

$<0.001$

$1.36(1.22-1.52)$

$<0.001$

$<0.001$

* Baseline group

Model 1: Adjusted for age and age ${ }^{2}$

Model 2: Adjusted for age, age ${ }^{2}$, Index of Multiple Deprivation quintiles, current smoking status and the presence or absence of the following long term

conditions: cancer, coronary heart disease, chronic kidney disease, COPD, dementia, depression, diabetes, epilepsy, heart failure, hypertension, severe mental illness, stroke. 
Table 5: Effect of alcohol consuption category on all-cause mortality by smoking status and deprivation quintile

\begin{tabular}{|c|c|c|c|c|c|c|c|c|}
\hline \multirow[b]{2}{*}{ Units } & \multicolumn{2}{|c|}{ Non-smoker } & \multicolumn{2}{|l|}{ Smoker } & \multicolumn{2}{|c|}{ Deprivation quintile 1-4 } & \multicolumn{2}{|c|}{$\begin{array}{c}\text { Deprivation quintile } 5 \\
\text { (most deprived) }\end{array}$} \\
\hline & HR (95\% CI) & $\mathbf{P}$ & HR $(95 \%$ CI $)$ & $\mathbf{P}$ & $\begin{array}{l}\text { HR (95\% } \\
\text { CI) }\end{array}$ & & HR $(95 \%$ CI) & $\mathbf{P}$ \\
\hline $1-7$ & $1 *$ & & $2.05(1.83-2.29)$ & $<0.001$ & $1 *$ & & $1.31(1.18-1.46)$ & $<0.001$ \\
\hline 8-14 & $0.97(0.90-1.05)$ & 0.495 & $2.20(1.94-2.50)$ & $<0.001$ & $\begin{array}{c}0.97(0.91- \\
1.05)\end{array}$ & 0.528 & $1.41(1.20-1.66)$ & $<0.001$ \\
\hline $15-24$ & $0.89(0.79-1.01)$ & 0.074 & $2.77(2.38-3.23)$ & $<0.001$ & $\begin{array}{l}0.96(0.87- \\
1.07)\end{array}$ & 0.488 & $1.48(1.20-1.83)$ & $<0.001$ \\
\hline $25-34$ & $1.16(1.01-1.33)$ & 0.037 & $3.13(2.57-3.82)$ & $<0.001$ & $\begin{array}{c}1.24(1.09- \\
1.40)\end{array}$ & 0.001 & $1.74(1.26-2.40)$ & 0.001 \\
\hline $35+$ & $1.54(1.35-1.76)$ & $<0.001$ & $4.04(3.41-4.79)$ & $<0.001$ & $\begin{array}{c}1.55(1.36- \\
1.76)\end{array}$ & $<0.001$ & $3.01(2.40-3.79)$ & $<0.001$ \\
\hline None & $1.25(1.17-1.33)$ & $<0.001$ & $2.27(2.04-2.53)$ & $<0.001$ & $\begin{array}{l}1.26(1.17- \\
1.35)\end{array}$ & $<0.001$ & $1.56(1.36-1.79)$ & $<0.001$ \\
\hline Ex-drinker & $1.50(1.36-1.65)$ & $<0.001$ & $2.95(2.58-3.37)$ & $<0.001$ & $\begin{array}{c}1.51(1.37- \\
1.67)\end{array}$ & $<0.001$ & $1.89(1.60-2.24)$ & $<0.001$ \\
\hline Missing & $1.42(1.30-1.56)$ & $<0.001$ & $3.20(2.64-3.87)$ & $<0.001$ & $\begin{array}{c}1.47(1.35- \\
1.61) \\
\end{array}$ & $<0.001$ & $1.77(1.41-2.22)$ & $<0.001$ \\
\hline
\end{tabular}

* Baseline group

Adjusted for age, age ${ }^{2}$, sex, Index of Multiple Deprivation quintiles, current smoking status and the presence or absence of the following long term conditions: cancer, coronary heart disease, chronic kidney disease, COPD, dementia, depression, diabetes, epilepsy, heart failure, hypertension, severe mental illness, stroke. 


\section{Analysis of Interactions}

In the fully adjusted model for all patients, statistically significant interactions were found between alcohol consumption and smoking status $(\mathrm{p}<0.001)$ and between alcohol and deprivation quintiles $(p<0.001)$. Separate and combined effects for alcohol and smoking are shown in Table 5. Heavier drinking increased mortality risk independently of smoking status, but mortality risk was markedly higher among smokers across all drinking categories. The association between drinking and mortality was strongest for patients who consumed 35+ units per week and smoked (HR=4.04, 3.41-4.79), compared with non-smokers who consumed 1-7 units per week. The pattern of alcohol and smoking interaction was similar for male and female patients (see Supplementary Table S3).

For ease of presentation, separate and combined effects for alcohol and deprivation are shown for the most deprived quintile (Table 5). Hazard ratios for mortality were higher for all categories of alcohol consumption among patients in the most deprived quintile, but were highest for those who consumed $35+$ units per week $(\mathrm{HR}=3.01,2.40-3.79)$. The alcohol and deprivation interaction was similar for male and female patients (Supplementary Table S4).

\section{DISCUSSION}

This study provides evidence that heavier drinkers among adult NHS general practice patients with long term conditions die younger than lighter drinkers, independent of the influence of a range of possible confounders, including the conditions that characterise the study population. All-cause mortality increases among men and women drinking above 24 units, compared to those drinking at lower levels, but the risk of dying is particularly pronounced among drinkers of both sexes drinking above 35 units per week. Mortality is also elevated among both non-drinkers and ex-drinkers. Smoking and deprivation both increase mortality risk separately, and each modify the effects of alcohol consumption, increasing the risk of all-cause mortality. These findings are consistent with previous studies of alcohol, smoking and mortality (14-16) and alcohol, deprivation and mortality.(17, $\underline{18)}$

This study analysed over 13,000 deaths among a large sample of primary care patients. The scientific value of all-cause mortality as an outcome in relation to alcohol consumption continues to be debated, (19) though it's importance to policy-making, and to broader considerations of alcohol's effects on public health and society, is clear.(20) We have no reason to be concerned about information bias in ONS data used as the outcome. However, as with all studies based on primary care data bases, we are reliant on accurate and consistent recording of explanatory variables by practices. Missing data is an acknowledged weakness of CPRD, which may bias analyses and/or require complex methods of imputation.(21) A significant proportion of patients in our analysis had missing alcohol consumption 
data. We adopted the approach of most previous CPRD studies by including a missing category in our models, finding mortality rates among those with missing data to be high. The sensitivity analysis using multiple imputation found similar results. It was notable that $64 \%$ of patient with missing alcohol data were female, suggesting gender-related differences in patterns of clinical enquiries and/or under-recording, as found in previous studies.(10)

We analysed the most recent record of alcohol consumption available in the dataset in order to present a parsimonious and clear account of the relationship between drinking and mortality. We do know that drinking is a behaviour which varies considerably over time, and multiple measures of drinking are available in the dataset. Completeness of recording for lifestyle variables in CPRD has improved, (21) especially after introduction of the Quality Outcomes Framework (QOF), so more recent records may be more accurate, (the sensitivity analysis supported the findings of the main analysis). The approach we adopted means that misclassification bias is likely; as heavy drinkers become sicker they may reduce or cease drinking. We are also aware that the CPRD relies on patient reports of alcohol consumption and these substantially under-estimate levels of consumption ( 7$)$, meaning that reporting bias is also likely. Both will systematically bias findings of alcohol's contribution to mortality towards the null, meaning that the observed effects here are highly likely to be under-estimates of the true effects. Risks to health associated with drinking patterns, as opposed to overall consumption levels, were not accounted for in this study. Unmeasured variables may impact on the observed estimates, and there is a possibility that there are important sources of residual confounding which would lead to over-statement of the effects of drinking on mortality.

Previous primary care database studies have not addressed the full spectrum of unhealthy alcohol use, studied levels of consumption, or investigated a range of health conditions. The findings of this study provide real world evidence from primary care that is broadly confirmatory of the alcohol epidemiological evidence-base. Whether or not there is a j-shaped relationship with all-cause mortality in which small doses of alcohol offer cardio-protective benefits has been a key concern.(11, $\underline{20}$, 22) The choice of non-drinking reference categories has been shown to be particularly problematic as usually these comprise ex-drinkers or "sick quitters", whose mortality risk is as high as heavier drinkers. $(\underline{20})$ For these reasons we separated confirmed ex-drinkers from those who were not drinking any alcohol at the time of consultation, an approach supported by the observed high mortality rate of the former. It seems likely that only some of these non-drinkers will be lifetime abstainers, and others, for example, may have been advised to abstain to reduce symptoms of concern or to avoid drug interactions.

Using consumption rates of 1-7 UK units per week (mean $8 \mathrm{~g}$ of ethanol per day or less) as the reference category enabled analysis of the effects of increasing consumption on risk of death among drinkers, and we found that mortality risk did increase with increased consumption. In line with the 
revisions made in the Chief Medical Officers alcohol guidelines, $(\underline{23})$ we found a pattern of risk that was similar for men and women but mortality was elevated for patients drinking over 24, rather than 14 , units per week. The increased mortality risk from drinking alcohol in populations living with long term health conditions could result from greater susceptibility to the direct toxic effects of alcohol, or via exacerbation of chronic conditions themselves, or both. These hypotheses warrant investigation in studies of specific causes of death, across and within common long term conditions, and which use measures of drinking and changes in consumption patterns over time.

\section{Conclusions}

Our findings pose important questions for general practice and the NHS as a whole about what is currently being done to reduce avoidable deaths due to alcohol. There were an estimated 23,000 alcohol related deaths in 2014 in England, and over the past 20 years, the numbers of deaths have continued to increase.(ㄱ) This is in contrast to Scotland where deaths have reduced by approximately one third from their peak levels around a decade ago.(24) The years of life lost in England in 2015 were estimated to be 301,000 compared to 360,000 for tobacco (alcohol kills fewer people but at much younger ages).(ㅈ). The comparison with tobacco is instructive. Since the Smoking Kills White Paper of 1998 (25) the NHS has led a wider societal response that has effectively reduced the population burden. A similar response for alcohol has been lacking, yet taking action on alcohol fits well with the aspiration to deliver a radical upgrade in prevention called for in the NHS Five Year Forward View.(26)

A genuinely strategic approach to this complex and costly problem, as was successful with smoking, is arguably all the more necessary due to the key role the alcohol industry appears to play in influencing policy in England.(27) This study shows clearly that alcohol makes the existing work of the NHS in managing long-term conditions more difficult, and an NHS-led response is urgently required. 


\section{ACKNOWLEDGEMENTS}

Contributors: DS and JM designed the study, with technical input from TD and LH. DS extracted the data from CPRD and conducted the statistical analysis, with advice from LH. All authors contributed to data interpretation. DS and JM led the writing of the paper with critical review and approval of the final version from all authors.

Competing Interests: All authors have completed the Unified Competing Interest form (available on request from the corresponding author) and declare: no support from any organisation for the submitted work; no financial relationships with any organisations that might have an interest in the submitted work in the previous three years, no other relationships or activities that could appear to have influenced the submitted work.

Transparency statement: The lead author confirms this is an honest, accurate, and transparent account of the study being reported and that no important aspects of the study have been omitted.

Ethical approval: Ethical approval was not required.

Funding: This research received no specific grant from any funding agency in the public, commercial or not-for-profit sectors. 


\section{References}

1. World Health Organisation. Global status report on alcohol and health 2014. Geneva: World Health Organisation; 2014.

2. Forouzanfar MH, Alexander L, Anderson HR, Bachman VF, Biryukov S, Brauer M, et al. Global, regional, and national comparative risk assessment of 79 behavioural, environmental and occupational, and metabolic risks or clusters of risks in 188 countries, 1990-2013: a systematic analysis for the Global Burden of Disease Study 2013. The Lancet.386(10010):2287-323.

3. Public Health England. The Public Health Burden of Alcohol and the Effectivenness and CostEffectiveness of Alcohol Control Policies: An Evidence Review. London: Public Health England; 2016. 4. Balakrishnan R, Allender S, Scarborough P, Webster P, Rayner M. The burden of alcoholrelated ill health in the United Kingdom. Journal of Public Health. 2009;31(3):366-73.

5. National Audit Office. Reducing Alcohol Harm: health services in England for alcohol misuse 2008. London: National Audit Office; 2008.

6. Cheeta S, Drummond C, Oyefeso A, Phillips T, Deluca P, Perryman K, et al. Low identification of alcohol use disorders in general practice in England. Addiction. 2008;103(5):766-73.

7. Khadjesari Z, Marston L, Petersen I, Nazareth I, Walters K. Alcohol consumption screening of newly-registered patients in primary care: a cross-sectional analysis. The British journal of general practice : the journal of the Royal College of General Practitioners. 2013;63(615):e706-12.

8. Brown J, West R, Angus C, Beard E, Brennan A, Drummond C, et al. Comparison of brief interventions in primary care on smoking and excessive alcohol consumption: a population survey in England. British Journal of General Practice. 2015;66(642):e1.

9. McCambridge J, Saitz R. Rethinking brief interventions for alcohol in general practice. BMJ. 2017;356.

10. Otete HE, Orton E, West J, Fleming KM. Sex and age differences in the early identification and treatment of alcohol use: a population-based study of patients with alcoholic cirrhosis. Addiction. 2015;110(12):1932-40.

11. Bell S, Daskalopoulou M, Rapsomaniki E, George J, Britton A, Bobak M, et al. Association between clinically recorded alcohol consumption and initial presentation of 12 cardiovascular diseases: population based cohort study using linked health records. BMJ. 2017;356.

12. Department for Communities and Local Government. The English Indices of Deprivation 2010 London: Department for Communities and Local Government; 2011.

13. Rubin DB. Multiple Imputation after 18+ Years. Journal of the American Statistical Association. 1996;91(434):473-89.

14. Hart CL, Davey Smith G, Gruer L, Watt GCM. The combined effect of smoking tobacco and drinking alcohol on cause-specific mortality: a 30 year cohort study. BMC Public Health. 2010;10(1):789.

15. Shaw BA, Agahi N. A prospective cohort study of health behavior profiles after age 50 and mortality risk. BMC Public Health. 2012;12(1):803.

16. Xu W, Zhang $X$, Gao Y, Xiang Y, Gao L, Zheng W. Joint effect of cigarette smoking and alcohol consumption on mortality. Preventive medicine. 2007;45.

17. Erskine S, Maheswaran R, Pearson T, Gleeson D. Socioeconomic deprivation, urban-rural location and alcohol-related mortality in England and Wales. BMC Public Health. 2010;10(1):99.

18. Bellis MA, Hughes K, Nicholls J, Sheron N, Gilmore I, Jones L. The alcohol harm paradox: using a national survey to explore how alcohol may disproportionately impact health in deprived individuals. BMC Public Health. 2016;16:111.

19. Rehm J, Roerecke M, Room R. All-Cause Mortality Risks for "Moderate Drinkers": What Are the Implications for Burden-of-Disease Studies and Low Risk-Drinking Guidelines? Journal of studies on alcohol and drugs. 2016;77(2):203-4; discussion 5-7.

20. Stockwell T, Zhao J, Panwar S, Roemer A, Naimi T, Chikritzhs T. Do "Moderate" Drinkers Have Reduced Mortality Risk? A Systematic Review and Meta-Analysis of Alcohol Consumption and AllCause Mortality. J Stud Alcohol Drugs. 2016;77(2):185-98. 
21. Herrett E, Gallagher AM, Bhaskaran K, Forbes H, Mathur R, van Staa T, et al. Data Resource Profile: Clinical Practice Research Datalink (CPRD). International journal of epidemiology.

2015;44(3):827-36.

22. Roerecke $M$, Rehm J. The cardioprotective association of average alcohol consumption and ischaemic heart disease: a systematic review and meta-analysis. Addiction. 2012;107(7):1246-60.

23. UK Chief Medical Officers' Alcohol Guidelines Review. Summary of the proposed new guidelines London: Department of Health https://www.gov.uk/government/consultations/healthrisks-from-alcohol-new-guidelines; 2016 [Available from:

https://www.gov.uk/government/consultations/health-risks-from-alcohol-new-guidelines.

24. Beeston C MR, Craig N, Gordon R, Graham L, MacPherson M, McAuley A, McCartney G, Robinson M, Shipton D, Van Heelsum A. Monitoring and Evaluating Scotland's Alcohol Strategy. Final Report. Edinburgh: NHS Health Scotland; 2016.

25. Department of Health. Smoking Kills. A White Paper on Tobacco. London: The Stationery Office; 1998.

26. NHS England. NHS: Five year forward view 2014 [Available from:

https://www.england.nhs.uk/ourwork/futurenhs/.

27. Hawkins B, McCambridge, J. Industry actors, think tanks and UK alcohol policy. American Journal of Public Health. 2014;104:1363-9. 


\section{Supplementary tables}

Table S1: Fully adjusted hazard ratios for all-cause mortality

\begin{tabular}{|c|c|c|c|c|}
\hline \multirow{2}{*}{ Consumption category } & \multirow[t]{2}{*}{ HR } & \multicolumn{2}{|c|}{$95 \% \mathrm{CI}$} & \multirow[t]{2}{*}{ p } \\
\hline & & & & \\
\hline $1-7$ & 1 & & & \\
\hline $8-14$ & & & & 83 \\
\hline & 0.99 & 0.93 & 1.06 & 7 \\
\hline $15-24$ & & & & 90 \\
\hline & 0.99 & 0.90 & 1.10 & 8 \\
\hline & & & & $<0$ \\
\hline $25-34$ & & & & .0 \\
\hline & 1.26 & 1.22 & 1.42 & 01 \\
\hline $35+$ & & & & $<0$ \\
\hline & 1.71 & 1.51 & 1.93 & 01 \\
\hline & & & & $<0$ \\
\hline None & & & & .0 \\
\hline & 1.23 & 1.36 & 1.62 & 01 \\
\hline Ex-drinker & & & & 0 \\
\hline & 1.48 & 1.36 & 1.62 & 01 \\
\hline Miscino & & & & $\begin{array}{r}<0 \\
0\end{array}$ \\
\hline & 1.44 & 1.32 & 1.57 & 01 \\
\hline & & & & 00 \\
\hline Age & 1.02 & 1.01 & 1.04 & 2 \\
\hline & & & & .0 \\
\hline $\mathrm{Age}^{2}$ & 1.00 & 1.00 & 1.00 & 01 \\
\hline & & & & .0 \\
\hline Male & 1.28 & 1.24 & 1.33 & 01 \\
\hline & & & & .0 \\
\hline Smoker & 2.11 & 2.00 & 2.23 & 01 \\
\hline Cancer & & & & .0 \\
\hline & 1.67 & 1.57 & 1.77 & 01 \\
\hline Coronary heart disease & & & & 05 \\
\hline & 1.07 & 1.00 & 1.16 & 7 \\
\hline Chronic kidney disease & & & & .0 \\
\hline & 0.74 & 0.69 & 0.80 & 01 \\
\hline $\mathrm{COPD}^{1}$ & & & & .0 \\
\hline & 1.28 & 1.20 & 1.36 & 01 \\
\hline Dementia & & & & .0 \\
\hline & 1.19 & 1.11 & 1.28 & 01 \\
\hline
\end{tabular}




\begin{tabular}{|c|c|c|c|c|}
\hline \multirow{2}{*}{ Depression } & & & & 05 \\
\hline & 0.95 & 0.91 & 1.00 & 1 \\
\hline \multirow[t]{2}{*}{ Diabetes } & & & & 00 \\
\hline & 1.09 & 1.02 & 1.17 & $\begin{array}{c}8 \\
<0\end{array}$ \\
\hline \multirow[t]{2}{*}{ Epilepsy } & & & & .0 \\
\hline & 1.64 & 1.32 & 2.05 & $\begin{array}{l}01 \\
<0\end{array}$ \\
\hline \multirow[t]{2}{*}{ Heart failure } & & & & .0 \\
\hline & 1.39 & 1.29 & 1.50 & $\begin{array}{l}01 \\
<0\end{array}$ \\
\hline \multirow[t]{2}{*}{ Hypertension } & & & & .0 \\
\hline & 0.67 & 0.65 & 0.73 & $\begin{array}{l}01 \\
<0\end{array}$ \\
\hline \multirow[t]{2}{*}{ Severe mental illness } & & & & .0 \\
\hline & 1.33 & 1.15 & 1.53 & 01 \\
\hline \multirow[t]{2}{*}{ Stroke } & & & & 00 \\
\hline & 1.09 & 1.03 & 1.16 & 3 \\
\hline \multicolumn{5}{|l|}{ IMD quintiles } \\
\hline \multirow[t]{2}{*}{1 (most affluent) } & 1 & & & \\
\hline & & & & 21 \\
\hline \multirow[t]{2}{*}{2} & 1.05 & 0.97 & 1.14 & 7 \\
\hline & & & & 00 \\
\hline \multirow[t]{2}{*}{3} & 1.13 & 1.03 & 1.24 & 8 \\
\hline & & & & 00 \\
\hline \multirow[t]{2}{*}{4} & 1.15 & 1.04 & 1.27 & 7 \\
\hline & & & & .0 \\
\hline 5 (most deprived) & 1.41 & 1.25 & 1.58 & 01 \\
\hline
\end{tabular}


Table S2: Hazard ratios for all-cause mortality by alcohol consumption category, with multiple imputation of missing alcohol consumption data and post April 2004 data only

\begin{tabular}{lcccc}
\hline Units & $\begin{array}{c}\text { Multiple } \\
\text { imputation } \\
\text { HR (95\% CI) }\end{array}$ & P & $\begin{array}{c}\text { Post 2004 } \\
\text { HR (95\% CI) }\end{array}$ & P \\
\hline $1-7^{*}$ & 1 & & 1 & \\
$8-14$ & $0.99(0.93-1.06)$ & 0.767 & $0.91(0.78-1.06)$ & 0.225 \\
$15-24$ & $1.00(0.90-1.10)$ & 0.937 & $0.88(0.74-1.04)$ & 0.138 \\
$25-34$ & $1.27(1.12-1.43)$ & $<0.001$ & $1.39(1.14-1.70)$ & 0.001 \\
$35+$ & $1.70(1.50-1.93)$ & $<0.001$ & $1.74(1.42-2.15)$ & $<0.001$ \\
None & $1.22(1.15-1.29)$ & $<0.001$ & $1.35(1.22-1.52)$ & $<0.001$ \\
Ex-drinker & $1.47(1.35-1.60)$ & $<0.001$ & $1.53(1.29-1.81)$ & $<0.001$ \\
Missing & - & - & $1.58(1.34-1.87)$ & $<0.001$ \\
\hline
\end{tabular}

* Baseline group

Adjusted for age, age ${ }^{2}$, sex, Index of Multiple Deprivation quintiles, current smoking status and the presence or absence of the following long term conditions: cancer, coronary heart disease, chronic kidney disease, chronic obstructive pulmonary disease, dementia, depression, diabetes, epilepsy, heart failure, hypertension, severe mental illness, stroke.

${ }^{1}$ Created from 5 imputed datasets including outcome status and all potential confounders in the models.

${ }^{2}$ Restricted to patients with data from 1st April 2004 onwards ( $\left.\mathrm{n}=48,007\right)$. 
Table S3: Effect of drinking category on all-cause mortality by smoking status for men and women

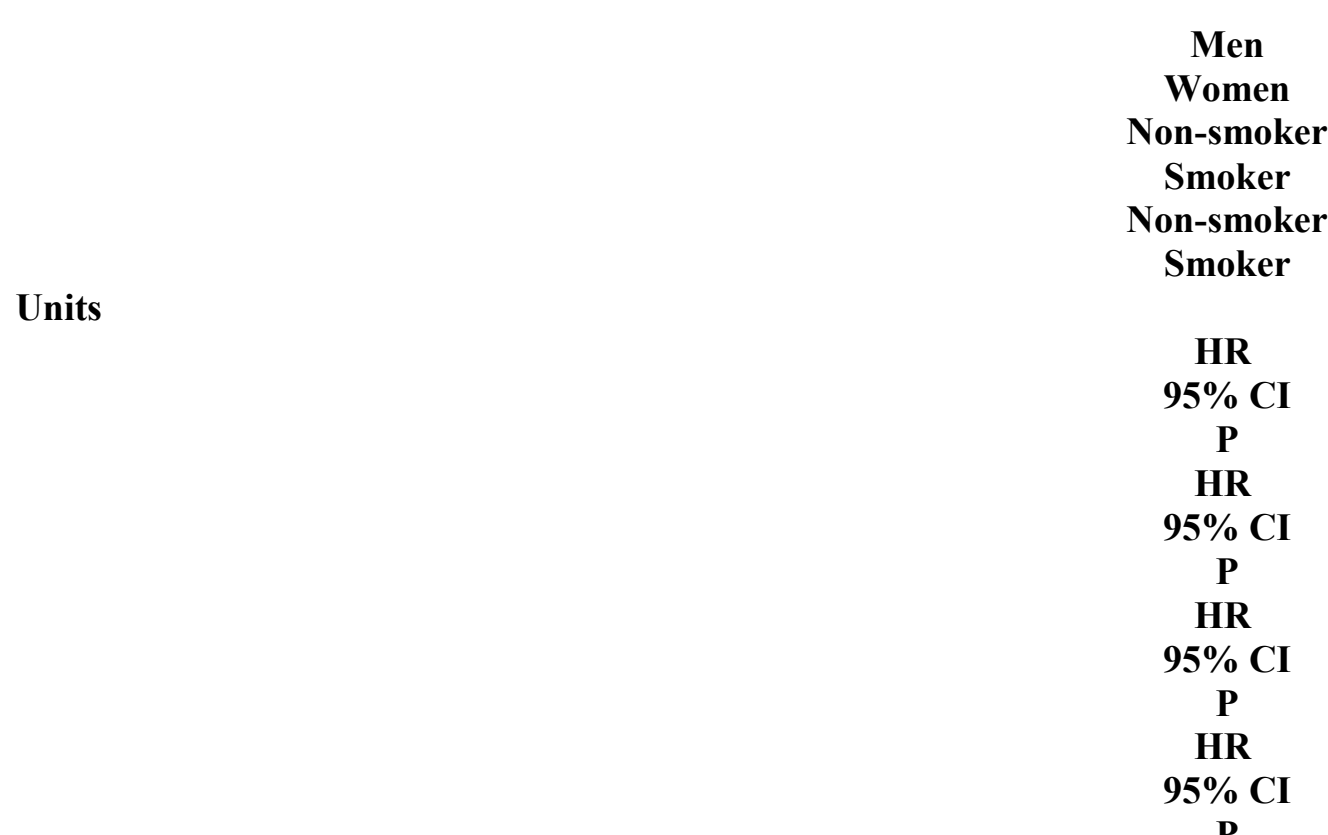

$1-7^{*}$

$$
\begin{gathered}
2.00 \\
1.73 \\
2.31 \\
<0.001
\end{gathered}
$$

$$
1
$$




$$
\begin{gathered}
2.06 \\
1.76 \\
2.42 \\
<0.001
\end{gathered}
$$

8-14

1.02

0.93

1.13

0.644

$$
2.15
$$

1.81

2.55

$<0.001$

0.89

0.81

0.99

0.035

2.24

1.78

2.82

$<0.001$

$15-24$

0.90

0.79

1.04

0.148

2.80

2.38

3.29

$<0.001$

0.89

0.70

1.14

0.346

2.65 
25-34

$<0.001$

1.21

1.04

1.41

0.014

3.01

2.36

3.84

$<0.001$

0.92

0.64

1.31

0.636

3.14

2.06

4.79

$<0.001$

$35+$

1.54

1.33

1.78

$<0.001$

3.93

3.31

4.65

$<0.001$

1.49

1.05

2.13

0.026

3.79

2.49 
None

1.28

1.17

1.40

$<0.001$

2.36

1.99

2.80

$<0.001$

1.22

1.13

1.31
$<0.001$

$<0.001$

2.19

1.92

2.47

$<0.001$

Ex-drinker

$$
\begin{gathered}
1.53 \\
1.35 \\
1.72 \\
<0.001 \\
2.75 \\
2.31 \\
3.26 \\
<0.001 \\
1.45 \\
1.28 \\
1.65 \\
<0.001 \\
3.18 \\
2.52 \\
3.99
\end{gathered}
$$


$<0.001$

Missing

$$
\begin{gathered}
1.52 \\
1.34 \\
1.72 \\
<0.001 \\
3.01 \\
2.46 \\
3.87 \\
<0.001 \\
1.33 \\
1.19 \\
1.50 \\
<0.001 \\
3.27 \\
2.56 \\
4.17
\end{gathered}
$$

\section{* Baseline group}

Adjusted for age, age ${ }^{2}$, Index of Multiple Deprivation quintiles and the presence or absence of the following long term conditions: cancer, coronary heart disease, chronic kidney disease, chronic obstructive pulmonary disease, dementia, depression, diabetes, epilepsy, heart failure, hypertension, severe mental illness, stroke. 
Table S4: Effect of drinking category on all-cause mortality by deprivation quintile for men and women

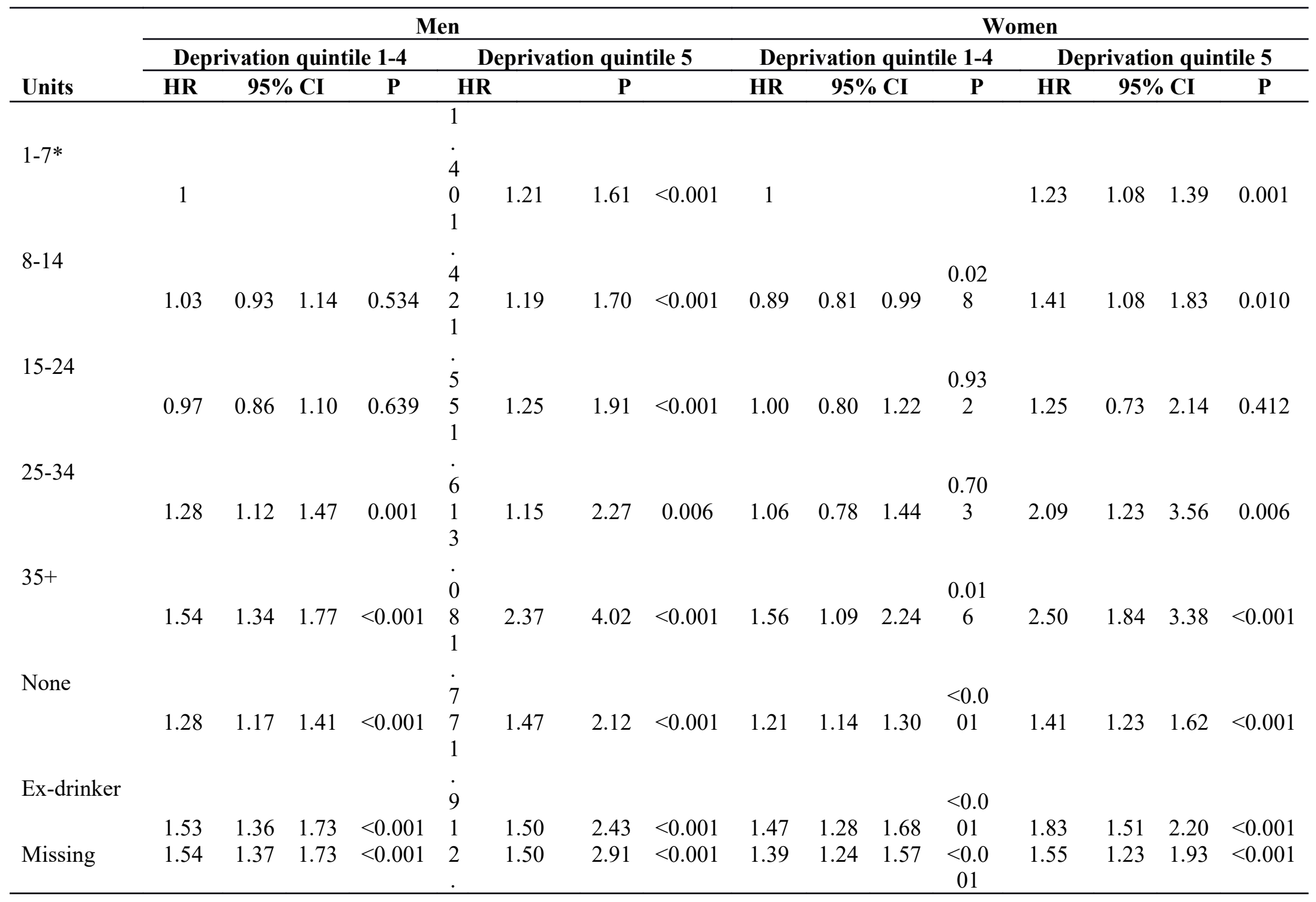


* Baseline group

Adjusted for age, age ${ }^{2}$, smoking status and the presence or absence of the following long term conditions: cancer, coronary heart disease, chronic kidney disease, chronic obstructive pulmonary disease, dementia, depression, diabetes, epilepsy, heart failure, hypertension, severe mental illness, stroke. 